\title{
Adverse Neurodevelopmental Effects of Dexamethasone Modeled in PCI 2 Cells: Identifying the Critical Stages and Concentration Thresholds for the Targeting of Cell Acquisition, Differentiation and Viability
}

\author{
Ruth R Jameson', Frederic J Seidler', Dan Qiao' and Theodore A Slotkin*,' \\ 'Department of Pharmacology \& Cancer Biology, Duke University Medical Center, Durham, NC, USA
}

\begin{abstract}
The use of dexamethasone (DEX) to prevent respiratory distress in preterm infants is suspected to produce neurobehavioral deficits. We used PCI 2 cells to model the effects of DEX on different stages of neuronal development, utilizing exposures from $24 \mathrm{~h}$ up to II days and concentrations from 0.01 to $10 \mu \mathrm{M}$, simulating subtherapeutic, therapeutic, and high-dose regimens. In undifferentiated cells, even at the lowest concentration, DEX inhibited DNA synthesis and produced a progressive deficit in the number of cells as evaluated by DNA content, whereas cell growth (evaluated by the total protein to DNA ratio) and cell viability (Trypan blue exclusion) were promoted. When cell differentiation was initiated with nerve growth factor, the simultaneous inclusion of DEX still produced a progressive deficit in cell numbers and promoted cell growth and viability while retarding the development of neuritic projections as monitored by the membrane/total protein ratio. Again, even $0.01 \mu$ M DEX was effective. We next assessed effects at mid-differentiation by introducing nerve growth factor for 4 days followed by coexposure to DEX. Although effects on cell number, growth, and neurite extension were still detectable, the outcomes were generally less notable. DEX also shifted the fate of PCI 2 cells away from the cholinergic phenotype and toward the adrenergic phenotype, with the maximum effect achieved at the outset of differentiation. Our results indicate that DEX directly disrupts neuronal cell replication, differentiation, and phenotype at concentrations below those required for the therapy of preterm infants, providing a mechanistic link between glucocorticoid use and neurodevelopmental sequelae. Neuropsychopharmacology (2006) 3 I, 1647-1658. doi: I 0. I 038/sj.npp. I 300967; published online 30 November 2005
\end{abstract}

Keywords: acetylcholine; brain development; catecholamines; glucocorticoids; neural cell differentiation; preterm delivery

\section{INTRODUCTION}

Glucocorticoids are typically given prophylactically to pregnant women undergoing preterm labor between the 24th and 34th weeks of gestation, or directly to preterm infants, in order to reduce the incidence of respiratory distress (Gilstrap et al, 1995). Currently, 10\% of all infants delivered in the US receive glucocorticoids, although only a small proportion are likely to have developed respiratory distress, so that hundreds of thousands of infants are treated unnecessarily (Matthews et al, 2002). Growing evidence indicates long-term liabilities from such treatment, including altered brain architecture (Murphy et al, 2001),

\footnotetext{
*Correspondence: Dr TA Slotkin, Department of Pharmacology \& Cancer Biology, Box 3813 DUMC, Duke University Medical Center, Durham, NC 27710, USA, Tel: + I 919681 8015, Fax: + I 919684 8197, E-mail: t.slotkin@duke.edu

Received 22 May 2005; revised 13 September 2005; accepted 12 October 2005

Online publication: 14 October 2005 at http://www.acnp.org/citations/ Npp I01405050342/default.pdf
}

and subsequent cognitive deficiencies (Doyle et al, 2000; Seckl, 2001; Yeh et al, 2004). Accordingly, recent reviews point out the drawbacks of the blanket use of glucocorticoids (Blackmon et al, 2002; Coe and Lubach, 2005; Newnham, 2001; Raff, 2004; Seckl, 2004), but nevertheless, the major comorbidities associated with preterm delivery make it difficult to assign a clear cause-and-effect relationship.

Animal studies of glucocorticoid effects on brain development, which avoid these comorbidities, have clarified the issue considerably. By themselves, glucocorticoids administered during development can lead to persistent stunting of somatic growth, outright cerebral atrophy, and endocrine disruption, along with a host of behavioral anomalies (Bohn, 1984; Fuxe et al, 1994, 1996; Gilad et al, 1998; Gould et al, 1997; Maccari et al, 2003; Matthews, 2000; Matthews et al, 2002; McEwen, 1992; Meaney et al, 1996; Weinstock, 2001; Welberg and Seckl, 2001). Nevertheless, most of the animal literature concerns doses of glucocorticoids well above those in clinical use and/or encompass prolonged exposure periods or periods outside the neurodeve- 
lopmental stages appropriate to mimic the use in humans. We recently developed a series of treatment models in the developing rat that take into account the stages of brain development appropriate to the targeted preterm human population, incorporating doses both within the therapeutic range and well below that level (Kreider et al, 2005a, b, 2006). Dexamethasone (DEX) treatments in late gestation or the early neonatal period that did not compromise long-term somatic growth, nevertheless disrupted neural cell acquisition, indices of neuritic outgrowth, synaptic activity, and cell signaling involved in trophic regulation of forebrain development (Kreider et al, 2005a), leading to long-term changes in cognition and motor activity (Kreider et al, 2005b), resembling those seen in models of prenatal stress (Bowman et al, 2004; Dean et al, 2001; Felszeghy et al, 2000; Muneoka et al, 1997). This provides strong evidence for a primary effect of glucocorticoids on brain development even at doses below those in clinical use.

Nevertheless, these in vivo models necessarily involve potential contributions from effects on the maternal-fetal unit, maternal-neonatal interactions, maternal, and neonatal neuroendocrine status, and a host of other indirect factors that converge on brain development and behavior. A direct proof of a mechanistic connection between glucocorticoids and abnormal neuronal development thus requires an in vitro system. Primary neurons do not maintain cell division in culture and do not provide a uniform population either in terms of cell types or differentiation state. In the current study, we utilized rat pheochromocytoma PC12 cells, a model for evaluating neuronal cell replication and differentiation (Teng and Greene, 1994). In the presence of nerve growth factor (NGF), the cells gradually exit the mitotic cycle and begin to differentiate, developing axonal projections, electrical excitability, and the characteristics of two distinct phenotypes, cholinergic, and catecholaminergic neurons (Fujita et al, 1989; Song et al, 1998; Teng and Greene, 1994). These specific phenotypes are highly targeted by DEX treatment in vivo (Ebert et al, 1997; Hu et al, 1996; Kreider et al, 2005a, b, 2006; Reznikov et al, 2004; Slotkin et al, 1991; Zahalka et al, 1993). Accordingly, the PC12 model is particularly appropriate to evaluate the mechanisms underlying the effects of DEX on neural cell replication and differentiation into defined phenotypes. Indeed, the medium required to maintain PC12 cell replication, differentiation, and growth entails the use of sera containing endogenous glucocorticoids (Qiao et al, 2005; Song et al, 1998; Teng and Greene, 1994), so that, as with the situation in vivo, effects of DEX are exerted over and above the requisite normal concentration required to maintain neural cell development. At the same time, as with all in vitro models, the cell cultures lack many features common to the developing brain, including the ability to evaluate neuronalglial interactions or more architectural aspects of regional development.

To recapitulate the effects seen in intact animals (Kreider et al, 2005a,2006), we evaluated the effects of different concentrations and durations of exposure to DEX in undifferentiated and differentiated states, evaluating indices of cell replication (radiolabeled thymidine incorporation into DNA), cell number, cell growth, viability, and phenotype. Each neural cell contains only a single nucleus (Winick and Noble, 1965), so that the DNA content reflects the total number of cells (Song et al, 1998); since DEX arrests mitosis in the $G_{0} / G_{1}$ phase (Greenberg et al, 2002), this relationship holds true even where DEX treatment affects cell acquisition. Indices of growth were provided by measurements of protein subfractions related to cell size and membrane surface area (Thai et al, 1996). In replicating cells, the total protein/DNA ratio rises with cell enlargement and the membrane/total protein ratio falls as a consequence of the decreased surface-to-volume ratio. On the other hand, with the onset of differentiation, the development of neuritic projections necessitates a rise in the relative contribution of membrane proteins. The effects on cell number, size, and cell surface area were compared to those on viability, evaluated by Trypan blue exclusion. To characterize the cholinergic and catecholaminergic phenotypes, we assessed the activities of choline acetyltransferase (ChAT) and tyrosine hydroxylase (TH), the respective biosynthetic enzymes for acetylcholine and dopamine (Teng and Greene, 1994).

Our focus was on two specific issues surrounding the use of glucocorticoids in preterm infants: characterizing the actions exerted at or below the concentrations relevant to clinical use, and identifying the spectrum of effects at the most relevant stages of neuronal development. Previous studies of glucocorticoids in this model have typically used excessive concentrations and have not focused on specific neurodevelopmental stages (Berse and Blusztajn, 1997; Ebert et al, 1997; Hagerty et al, 2001; Lucas and Thoenen, 1977; Schubert et al, 1980; Unsicker et al, 1978). Accordingly, the present study utilized DEX concentrations as low as $0.01 \mu \mathrm{M}$ and up to $10 \mu \mathrm{M}$. In humans, the typical levels after administration of a relatively low dose of $0.1-0.15 \mathrm{mg} / \mathrm{kg}$ is about $0.6 \mu \mathrm{M}$ when given directly to a preterm infant, or $0.06 \mu \mathrm{M}$ in the fetus when DEX is given to the mother (Charles et al, 1993; Osathanondh et al, 1977); as the recommended dose in preterm delivery is about three times higher (Gilstrap et al, 1995), our chosen dose range clearly spans the subtherapeutic to supratherapeutic range. We evaluated three different critical neurodevelopmental stages: undifferentiated cells that are undergoing active mitosis, early stages of differentiation in which cells are still dividing but are undergoing the transition to neuritic development and phenotypic specialization, and mid-differentiation in which the same processes are further developed. Again, these are stages that are most likely to be targeted by DEX, based on biochemical and morphological criteria from in vivo studies (Bohn, 1984; Murphy et al, 2001).

\section{METHODS}

\section{PC12 Cell Culture and Treatments}

As described previously (Song et al, 1998) PC12 cells (American Type Culture Collection, 1721-CRL) were grown in RPMI-1640 medium (Invitrogen, Carlsbad, CA) supplemented with $10 \%$ inactivated horse serum (Sigma Chemical Co., St Louis, MO), 5\% fetal bovine serum (Sigma), and $50 \mu \mathrm{g} / \mathrm{ml}$ penicillin-streptomycin (Invitrogen); the added sera thus expose the cells to endogenous glucocorticoids. 
Cells were incubated with $7.5 \% \quad \mathrm{CO}_{2}$ at $37^{\circ} \mathrm{C}$ and the medium was changed every 2-3 days. Because of the clonal instability of the PC12 cell line (Fujita et al, 1989), the experiments were performed on cells that had undergone fewer than five passages and studies were repeated several times with different batches of cells. For evaluation of DEX effects of different durations in the undifferentiated state, cells were plated on $60 \mathrm{~mm}$ poly-L-lysine-coated plates at various initial densities so as to achieve approximately $70 \%$ confluence at the time of each determination, in order to avoid complete confluence and excessive clumping at the longest time points. At $24 \mathrm{~h}$ after plating, the medium was changed to include concentrations of DEX phosphate (Sigma) ranging from 0.01 to $10 \mu \mathrm{M}$.

For studies involving DEX exposure in differentiating cells, the initial plating density was held constant at $0.5 \times 10^{6}$ cells per $60 \mathrm{~mm}$ plate or $3.5 \times 10^{6}$ cells per $100 \mathrm{~mm}$ plate. At $24 \mathrm{~h}$ after plating, the medium was changed to include $50 \mathrm{ng} / \mathrm{ml}$ of NGF (Sigma) with or without the addition of different concentrations of DEX. DEX effects were examined under two different conditions, the first in which DEX was present from the outset of differentiation (DEX added simultaneously with NGF), and the second in which cells were allowed to begin differentiation before the addition of DEX (4d NGF pretreatment followed by DEX). Each culture was examined under a microscope to verify the outgrowth of neurites after the addition of NGF.

\section{DNA Synthesis}

To initiate the measurement of DNA synthesis, the medium was changed to include $1 \mu \mathrm{Ci} / \mathrm{ml}$ of $\left[{ }^{3} \mathrm{H}\right]$ thymidine (specific activity, $2 \mathrm{Ci} / \mathrm{mmol}$; GE Healthcare, Piscataway, NJ) along with the continued inclusion of DEX. After $1 \mathrm{~h}$, the medium was aspirated and cells were harvested in $3.5 \mathrm{ml}$ of ice-cold water. Duplicate aliquots of each sample were treated with $10 \%$ trichloroacetic acid and sedimented at $1000 \mathrm{~g}$ for $15 \mathrm{~min}$ to precipitate nucleic acids and proteins. The resulting pellet was washed once with additional trichloroacetic acid and then with $75 \%$ ethanol. The final pellet was hydrolyzed with $1 \mathrm{M} \mathrm{KOH}$ overnight at $37^{\circ} \mathrm{C}$, neutralized with $6 \mathrm{M} \mathrm{HCl}$, and the DNA was precipitated with ice-cold 5\% trichloroacetic acid and resedimented. The supernatant solution, comprising solubilized RNA and protein, was discarded. The DNA-containing pellet was hydrolyzed in 5\% trichloroacetic acid for $15 \mathrm{~min}$ at $90^{\circ} \mathrm{C}$, resedimented, and an aliquot of the supernatant solution was counted for radiolabel. Another aliquot was assayed for DNA spectrophotometrically by absorbance at $260 \mathrm{~nm}$. Previous work has demonstrated quantitative recovery of DNA by these techniques (Bell et al, 1986; Slotkin et al, 1984). Incorporation values were corrected to the amount of DNA present in each culture to provide an index of DNA synthesis per cell.

\section{Cell Number, Size, and Viability}

The medium was aspirated and the culture was rinsed with $1 \mathrm{ml}$ of a buffer consisting of $0.9 \% \mathrm{NaCl}$ and $10 \mathrm{mM}$ sodium phosphate ( $\mathrm{pH}$ 7.4). Cells were harvested in ice-cold buffer, homogenized (Polytron, Brinkmann Instruments, West- bury, NY) and aliquots were withdrawn for measurements of DNA and total protein (Trauth et al, 2000). To prepare the cell membrane fraction, the homogenates were sedimented at $40000 \mathrm{~g}$ for $10 \mathrm{~min}$ and the pellet was washed and resedimented. Aliquots of the final resuspension were then assayed for membrane protein. Cell viability was assessed in separate cultures. The medium was changed to include trypan blue (Sigma; 1 volume per 2.5 volumes of medium) and cells were examined for staining under $400 \times$ magnification, counting an average of 100 cells per field in four different fields per culture.

\section{Enzyme Activities}

Cells were harvested as already described and were lysed by homogenization in a ground-glass homogenizer fitted with a ground-glass pestle, using a buffer consisting of $154 \mathrm{mM}$ $\mathrm{NaCl}$ and $10 \mathrm{mM}$ sodium-potassium phosphate ( $\mathrm{pH} 7.4$ ). ChAT assays (Lau et al, 1988) were conducted with $40 \mu \mathrm{g}$ of protein in $60 \mu \mathrm{l}$ of a buffer consisting of $60 \mathrm{mM}$ sodium phosphate ( $\mathrm{pH}$ 7.9), $200 \mathrm{mM} \mathrm{NaCl}, 20 \mathrm{mM}$ choline chloride, $17 \mathrm{mM} \mathrm{MgCl}_{2}, 1 \mathrm{mM}$ EDTA, $0.2 \%$ Triton X-100, $0.12 \mathrm{mM}$ physostigmine (Sigma), and $0.6 \mathrm{mg} / \mathrm{ml}$ bovine serum albumin (Sigma), containing a final concentration of $50 \mu \mathrm{M}\left[{ }^{14} \mathrm{C}\right.$ ]acetyl-coenzyme A (specific activity $44 \mathrm{mCi}$ / mmol, diluted with unlabeled compound to $6.7 \mathrm{mCi} / \mathrm{mmol}$; PerkinElmer Life Sciences, Boston, MA). Blanks contained homogenization buffer instead of the tissue homogenate. Samples were preincubated for $15 \mathrm{~min}$ on ice, transferred to a $37^{\circ} \mathrm{C}$ water bath for $30 \mathrm{~min}$, and the reaction terminated by placing the samples on ice. Labeled acetylcholine was then extracted, counted, and the activity determined relative to DNA or total protein.

$\mathrm{TH}$ activity was measured using $\left[{ }^{14} \mathrm{C}\right]$ tyrosine as a substrate and trapping the evolved ${ }^{14} \mathrm{CO}_{2}$ after coupled decarboxylation with dopa decarboxylase (Lau et al, 1988). Homogenates were sedimented at $26000 \mathrm{~g}$ for $10 \mathrm{~min}$ to remove storage vesicles containing catecholamines, which interfere with TH activity, and assays were conducted with $100 \mu \mathrm{l}$ aliquots of the supernatant solution in a total volume of $550 \mu \mathrm{l}$. Each assay ( $\mathrm{pH}$ 6.1) contained final concentrations of $910 \mu \mathrm{M} \mathrm{FeSO}, 55 \mu \mathrm{M}$ unlabeled L-tyrosine (Sigma) $9.1 \mu \mathrm{M}$ pyridoxal phosphate (Sigma), $36 \mu \mathrm{M} \beta$-mercaptoethanol, and $180 \mu \mathrm{M}$ 2-amino-6,7-dimethyl-4-hydroxy5,6,7,8-tetrahydropteridine $\mathrm{HCl}$ (Sigma), all in a buffer of $180 \mathrm{mM}$ sodium acetate and $1.8 \mathrm{mM}$ sodium phosphate $(\mathrm{pH}$ 6.1). Each assay contained $0.5 \mu \mathrm{Ci}$ of generally-labeled $\left[{ }^{14} \mathrm{C}\right]$ tyrosine (specific activity, $438 \mathrm{mCi} / \mathrm{mmol}$; Sigma) as substrate and blanks contained buffer in place of the homogenate.

\section{Data Analysis}

Data are presented as means and SE. For each type of study, treatment differences were first evaluated with a global analysis of variance (ANOVA) incorporating all variables: Dex concentration, time, and the presence or absence of NGF. Based on the interactions of Dex with the other factors, data were then subdivided for lower-order tests, followed by Fisher's Protected Least Significant Difference to establish individual values that differed from the corresponding controls. Because many of the comparisons 
involved large changes, even over an order of magnitude, the multivariate tests required log-transformation of the data before ANOVAs could be run. To ensure that transformation was applied in an unbiased fashion, all data sets were evaluated with Bartlett's test prior to ANOVA and reevaluated after log-transformation to ensure that the transformation resulted in equal variances. For comparisons that passed Bartlett's test without transformation, we nevertheless conducted an additional ANOVA with log transformation to verify that statistical significance was maintained.

For all tests, significance was assumed at $p<0.05$.

\section{RESULTS}

\section{Cell Acquisition, Growth, and Viability in Undifferentiated Cells}

In undifferentiated PC12 cells, DEX concentrations as low as $0.01 \mu \mathrm{M}$ elicited significant inhibition of mitotic activity, as shown by a reduction in $\left[{ }^{3} \mathrm{H}\right]$ thymidine incorporation into DNA (Figure 1). The effect plateaued at about $60 \%$ inhibition between 1 and $10 \mu \mathrm{M}$. Prolonged exposure to DEX did not elicit desensitization of the effect. By $72 \mathrm{~h}$, at which time the rate of DNA synthesis in control cells had slowed by nearly half, DEX nevertheless produced an inhibitory profile that was similar to that seen earlier (significant main effect of DEX dose but no significant interaction of dose $\times$ time). Because of the reduced overall synthetic rate, the lowest DEX concentrations did not produce statistically significant effects at $72 \mathrm{~h}$ but the magnitude of the reduction was the same as, and statistically indistinguishable from, that seen at $24 \mathrm{~h}$.

The consequences of reduced mitotic activity were readily evident in a progressive reduction in DNA content in

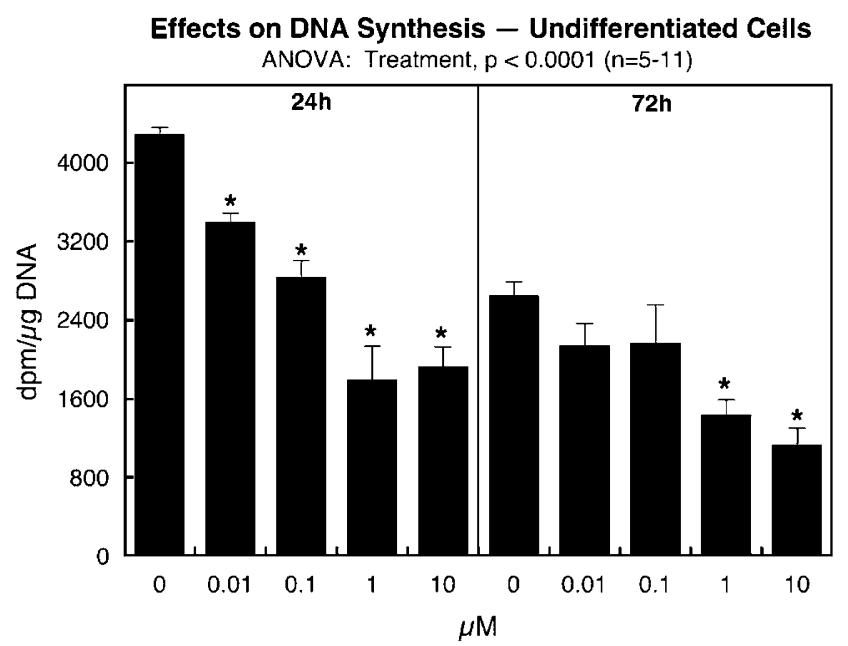

Figure I Concentration-response and time-response relationships for the effects of DEX on $\left[{ }^{3} \mathrm{H}\right]$ thymidine incorporation into DNA in undifferentiated cells. Cells were plated at different initial densities to achieve approximately the same degree of confluence at the two time points (see Methods). ANOVA across all concentrations and both time points is shown at the top of the panel and the number of determinations at each time and concentration is shown in parentheses. * Denotes individual values that differ from the corresponding control $(0 \mu \mathrm{M})$. undifferentiated cells, indicative of reduced cell number (Figure 2a). After $168 \mathrm{~h}$ of DEX exposure, even the lowest concentration elicited reductions of over $30 \%$ and higher concentrations ranging from 0.1 to $10 \mu \mathrm{M}$ evoked deficits of more than 50\%. In contrast, DEX did not impair cell growth and actually evoked significant increases in the total protein/DNA ratio, signifying larger cell size (Figure 2b). Again, these effects became progressively greater with time, were significant even at $0.01 \mu \mathrm{M}$ DEX and plateaued between 0.1 to $10 \mu \mathrm{M}$. In keeping with perikaryal enlargement, the effects of DEX on the membrane/total protein ratio showed an inverse relation to the total protein/DNA ratio (Figure 2c); larger cells have a reduced surface-tovolume ratio, reflected in deficits in this index of membrane complexity. Finally, we used Trypan blue to evaluate the effects of the highest concentration of DEX $(10 \mu \mathrm{M})$ on viability in undifferentiated PC12 cells (Figure 2d). DEX did not decrease viability at any time and in fact, improved viability with prolonged exposure, as evidenced by a significant reduction in stained (nonviable) cells at $168 \mathrm{~h}$.

\section{Cell Acquisition, Growth, and Viability in Differentiating Cells}

Unlike the studies in undifferentiated cells, in the experiments with addition of NGF, cells were plated at the same initial density regardless of the evaluated time point, so that longitudinal changes reflect the progression of differentiation. Previous studies indicate that cell replication continues, albeit at a reduced rate, for at least 10 days after the addition of NGF (Song et al, 1998), and in keeping with that finding, DNA content continued to rise through $264 \mathrm{~h}$ in culture (Figure 3a); indeed, the total number of cells approximately doubled between $168 \mathrm{~h}$ and $264 \mathrm{~h}$. When DEX was administered from the outset of differentiation (ie simultaneously with the addition of NGF), it still elicited significant reductions in cell number, albeit to a lesser extent than had been seen in undifferentiated cells. The lowest concentration produced about $10 \%$ inhibition whereas deficits were about $30 \%$ at higher DEX concentrations.

In keeping with its ability to enhance growth and differentiation, NGF by itself produced more than a doubling in the total protein/DNA ratio as compared to undifferentiated cells but DEX administered from the start of differentiation nevertheless was still able to promote growth even further (Figure 3b). As before, significant effects were seen even at $0.01 \mu \mathrm{M}$ DEX with plateauing of the effect at the higher concentrations, showing a maximal increase of about $25 \%$. In accord with neurite formation, NGF by itself increased the membrane/total protein ratio by $50 \%$ above the levels seen in undifferentiated cells $(15 \%$ membrane protein $v s \quad 10 \%$ in undifferentiated cells), whereas simple perikaryal enlargement would have reduced the ratio. DEX administration evoked deficits in the membrane/total protein ratio, although concentrations above $0.01 \mu \mathrm{M}$ were required to produce a significant effect and the magnitude of the decrements was slightly smaller than for the other indices (Figure 3c). Trypan blue exclusion did not demonstrate any decrement in viability in the DEX-exposed cells (Figure 3d). On the contrary, there was a significant overall increase in 
a

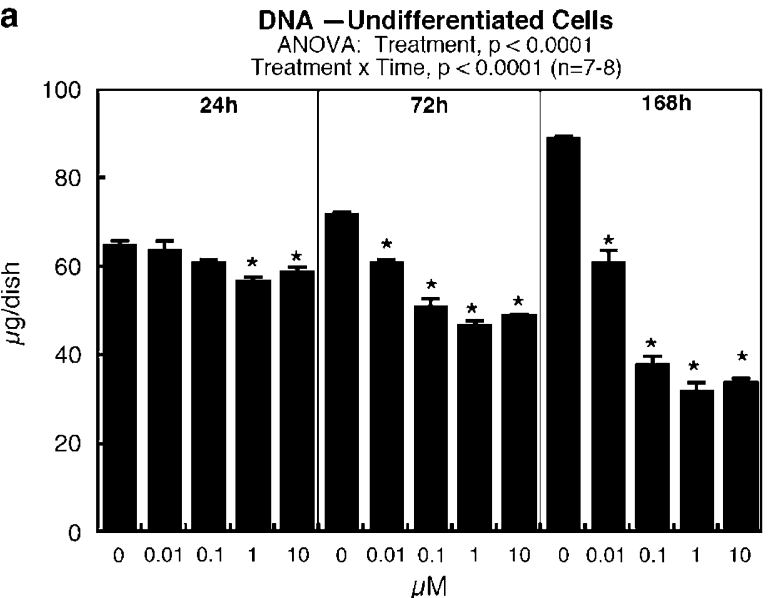

C Membrane/Total Protein Ratio - Undifferentiated Cells

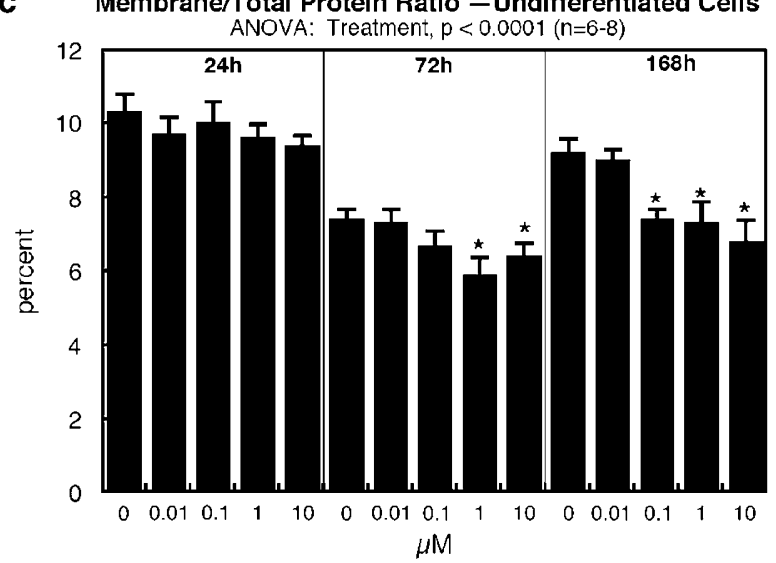

b Total Protein/DNA Ratio - Undifferentiated Cells ANOVA: Treatment, $p<0.0001$ Treatment $x$ Time, $p<0.0001(n=6-8)$

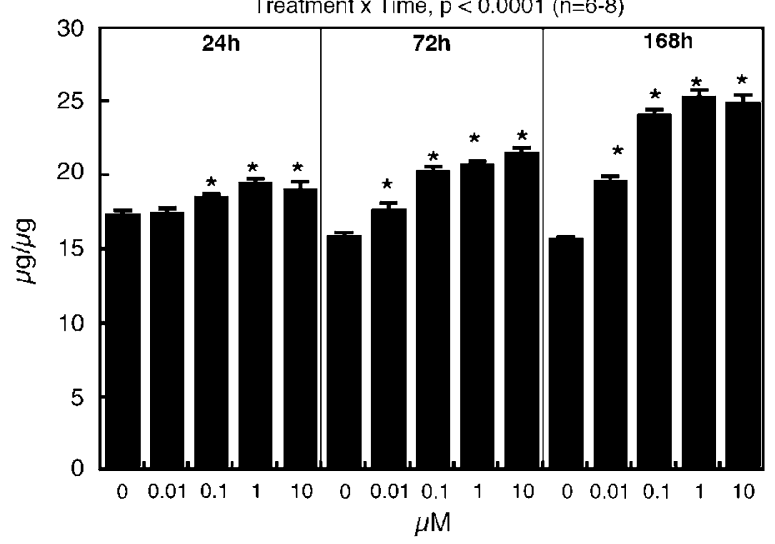

d

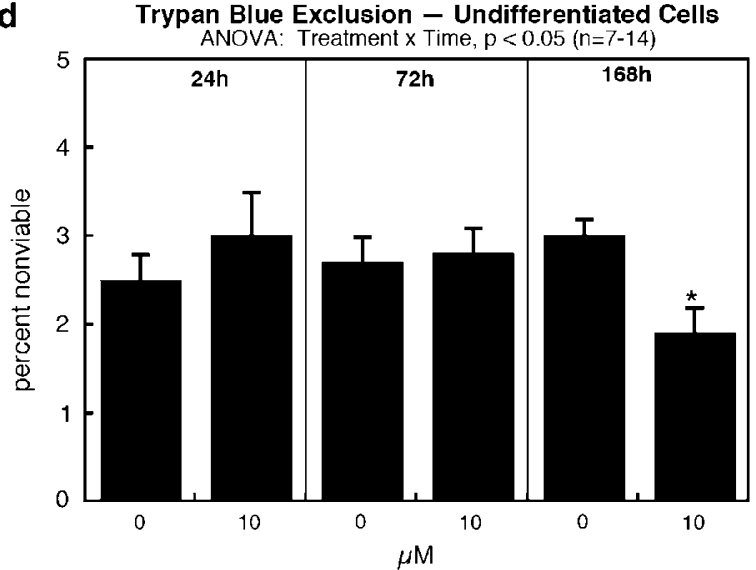

Figure 2 Concentration-response and time-response relationships for the effects of DEX on cell number, cell size and viability in undifferentiated cells: (a) DNA concentration, (b) total protein/DNA ratio, (c) membrane/total protein ratio, and (d) Trypan blue exclusion. Cells were plated at different initial densities to achieve approximately the same degree of confluence at the various time points (see Methods); accordingly, apparent time-related changes in the absolute values for DNA are not meaningful. ANOVA across all concentrations and time points is shown at the top of each panel and the number of determinations at each time and concentration is shown in parentheses. * Denotes individual values that differ from the corresponding control $(0 \mu \mathrm{M})$.

viability (reduced staining); values for the individual time points did not achieve significance separately because of the small sample size but the effect across the two time points was significant. Just as reported previously (Qiao et al, 2005) NGF treatment alone produced a progressive rise in nonviable cells, which likely involves the increase in oxidative stress attending the early stages of differentiation and neurite formation.

\section{Cell Acquisition, Growth, and Viability at Mid-Differentiation}

To pursue the issue of critical periods of vulnerability, we next allowed cells to undergo NGF-induced differentiation for 4 days before beginning treatment with DEX; accordingly, the 24,72 or $168 \mathrm{~h}$ time points for DEX treatment reflect 5,7 , or 11 days' total exposure to NGF, respectively. Under these conditions, new cells continued to be formed, as evidenced by the progressive rise in DNA content under control conditions (Figure 4a). DEX administration still interfered with cell acquisition with a low concentration threshold (significant effects even at $0.01 \mu \mathrm{M}$ ) and a maximum deficit of about $30 \%$, approximately the same profile as had been seen when DEX was included at the initiation of differentiation. Similarly, DEX was still promotional for cell growth as indicated by significant increases in the total protein/DNA ratio (Figure $4 \mathrm{~b}$ ). The later introduction of DEX also interfered with the subsequent rise in membrane/total protein ratio, consistent with inhibitory actions directed toward neurite formation (Figure 4c), although the effects were somewhat smaller in magnitude than had been seen when DEX was included from the outset of NGF-induced differentiation (15\% maximum deficit compared to 25\%). Notably, this DEX regimen failed to produce an improvement in cell viability, as there were no significant reductions in Trypan blue staining (Figure $4 \mathrm{~d}$ ).

\section{Cholinergic vs Catecholaminergic Phenotype}

To determine effects on phenotype, we turned to enzymatic measures characterizing cholinergic and catecholaminergic subpopulations, ChAT and TH, respectively. Since TH is known to have a glucocorticoid response element in its promoter region (Hagerty et al, 2001), we first concentrated on the effects of DEX on ChAT activity in undifferentiated 
a

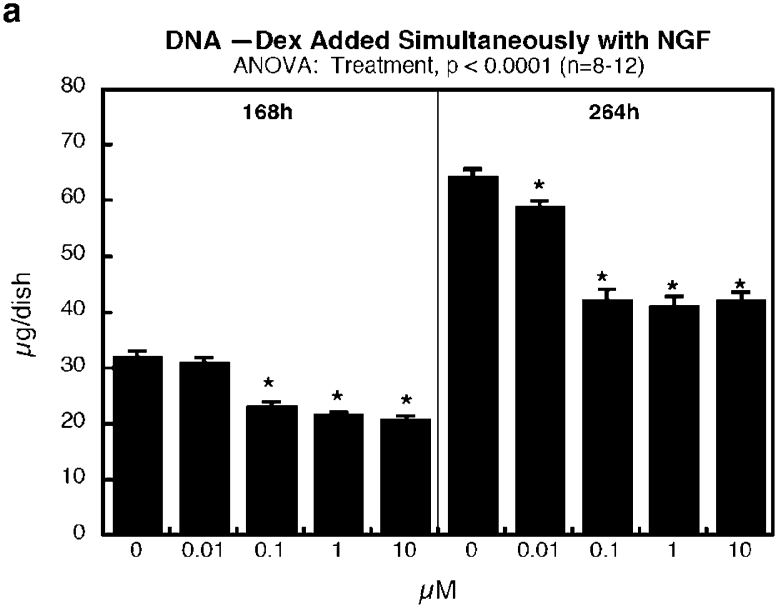

C

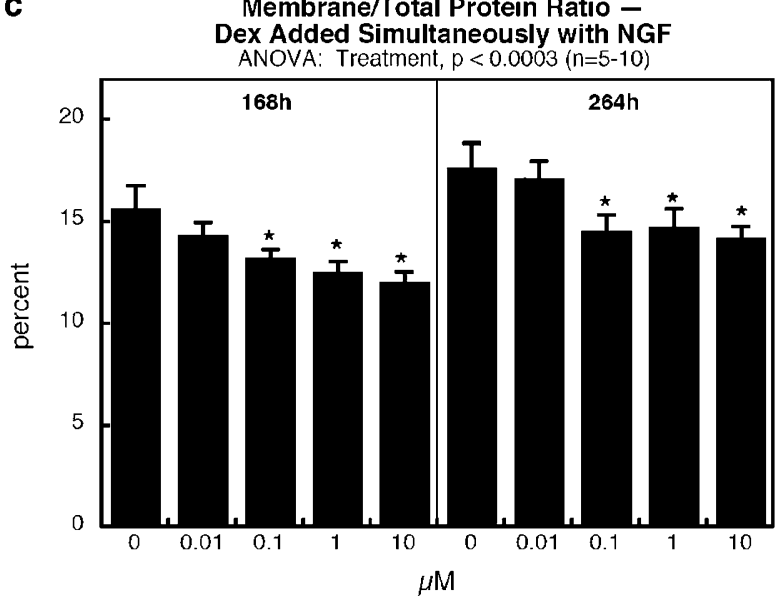

b

Total Protein/DNA Ratio -

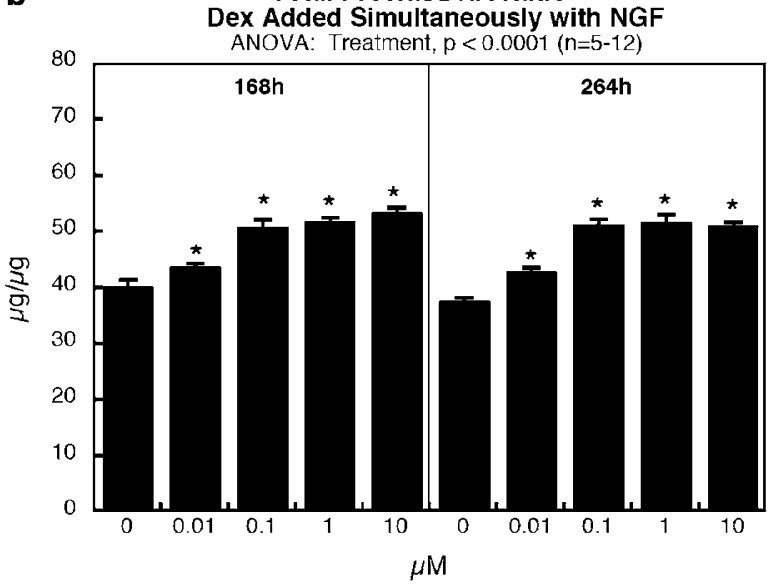

d

Trypan Blue Exclusion -

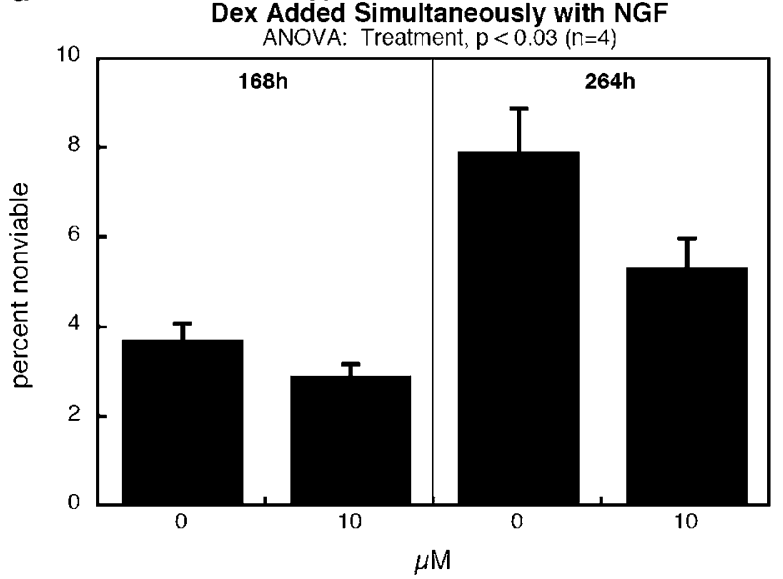

Figure 3 Concentration-response and time-response relationships for the effects of DEX on cell number, cell size and viability in cells undergoing NGFinduced differentiation, with DEX added simultaneously with NGF: (a) DNA concentration, (b) total protein/DNA ratio, (c) membrane/total protein ratio, and (d) Trypan blue exclusion. Cells were plated at the same initial density for each time point (see Methods). ANOVA across all concentrations and time points is shown at the top of each panel and the number of determinations at each time and concentration is shown in parentheses. $*$ Denotes individual values that differ from the corresponding control $(0 \mu \mathrm{M})$.

vs differentiating PC12 cells. Considering ChAT activity per cell (ie per unit DNA), $72 \mathrm{~h}$ of DEX exposure evoked a significant increase but only at relatively high concentrations (Figure 5a). The addition of NGF evoked a much larger increase in ChAT/DNA (note different scale for the right panel in Figure 5a). When DEX was included from the onset of differentiation (added simultaneously with NGF), it interfered with the promotional effect of NGF, evoking significant decrements in ChAT even at $0.01 \mu \mathrm{M}$, with a maximal reduction of about $40 \%$ compared to control values. Nevertheless, it should be noted that DEX did not totally block the increase in ChAT caused by NGF-induced differentiation, since the values in the DEX groups were still more than twice those of the starting point in undifferentiated cells.

As both NGF and DEX alter cell size, it is important to consider the effects on ChAT expression relative to changes in other proteins. In undifferentiated cells, in contrast to the increase in ChAT seen on a per cell basis, DEX treatment reduced ChAT per unit protein (Figure 5b), indicating that, although it is promotional for ChAT, the enzyme is increased to a lesser extent than are the other proteins associated with cell enlargement. NGF still increased ChAT robustly when considered as activity per unit protein (note different scale for the right panel in Figure 5b) and DEX remained strongly inhibitory for the expression of ChAT in the differentiating cells.

Given the known ability of high concentrations of DEX to increase $\mathrm{TH}$ in undifferentiated PC12 cells (Hagerty et al, 2001; Lucas and Thoenen, 1977), we evaluated the threshold for these effects by assessing $\mathrm{TH}$ after $72 \mathrm{~h}$ of exposure to the lowest DEX concentration, $0.01 \mu \mathrm{M}$. There was unequivocal $\mathrm{TH}$ induction, whether assessed as activity per cell or per unit protein: control $(n=11), 354 \pm 13 \mathrm{pmol} / \mathrm{h} / \mu \mathrm{g}$ DNA, $18.5 \pm 0.7 \mathrm{pmol} / \mathrm{h} / \mu \mathrm{g}$ protein; DEX $0.01 \mu \mathrm{M}(n=10)$, $428 \pm 17\left(\mathrm{~F}_{1,19}=12.5, \quad p<0.003\right)$, and $23.6 \pm 0.8\left(\mathrm{~F}_{1,19}=\right.$ 23.6, $p<0.0001)$, respectively.

Finally, we explored the dichotomy of DEX effects targeting the cholinergic and catecholaminergic phenotypes during differentiation by evaluating $\mathrm{TH}$ and ChAT activities in cells pretreated with NGF for 4 days, followed by the introduction of DEX. Again, we focused on the lowest DEX concentration $(0.01 \mu \mathrm{M})$, well below those achieved in therapeutic settings. NGF by itself evoked robust increases in 
a

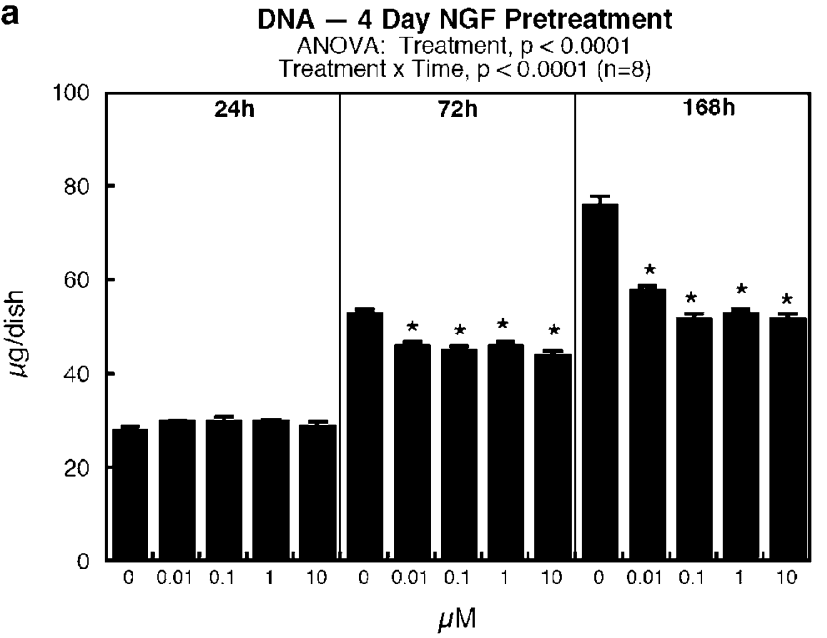

C Membrane/Total Protein Ratio - 4 Day NGF Pretreatment ANOVA: Treatment, $\mathrm{p}<0.01(\mathrm{n}=7-8)$

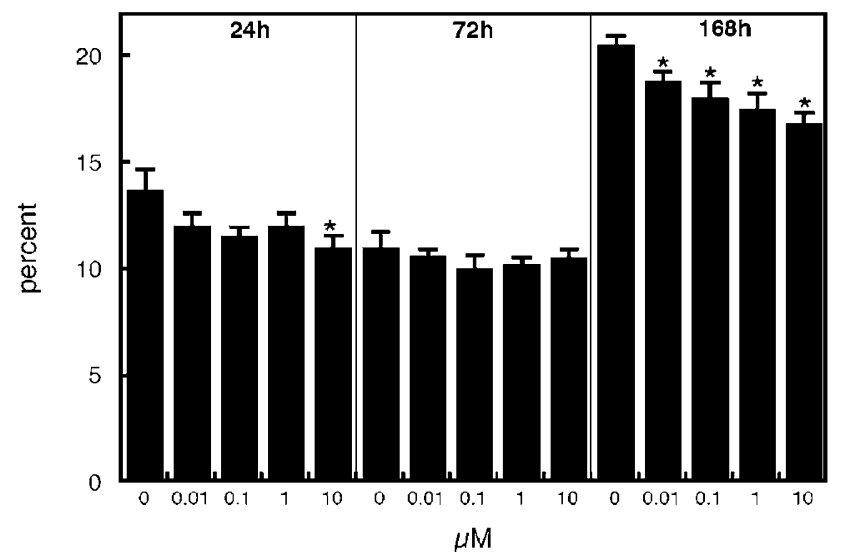

b

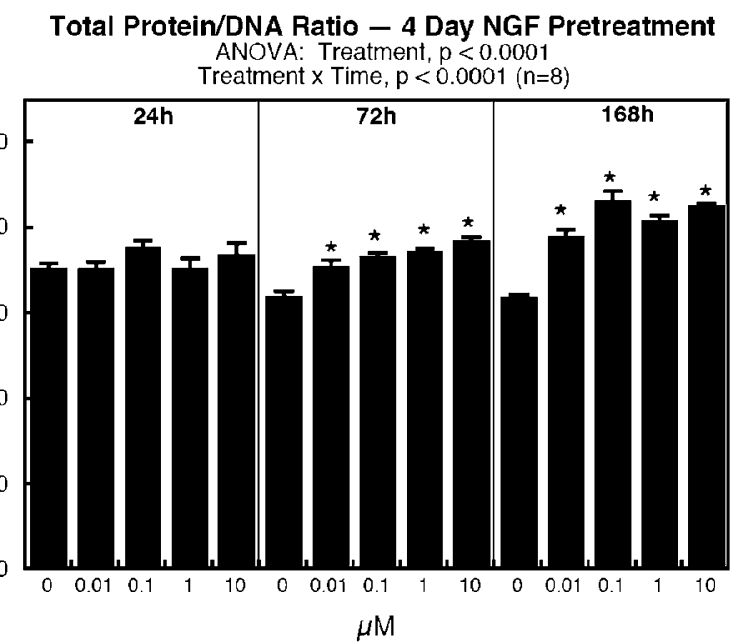

d

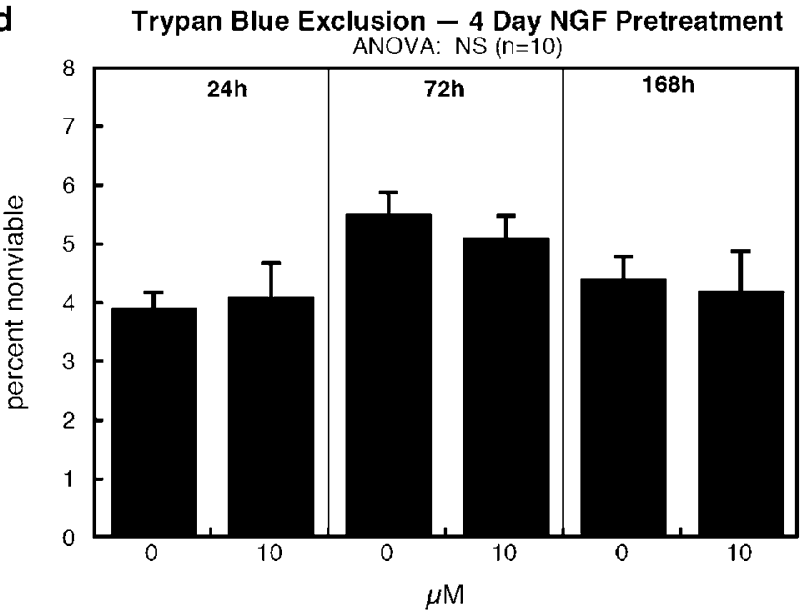

Figure 4 Concentration-response and time-response relationships for the effects of DEX on cell number, cell size, and viability in cells undergoing NGFinduced differentiation, with DEX added after 4 days of NGF pretreatment: (a) DNA concentration, (b) total protein/DNA ratio, (c) membrane/total protein ratio, and (d) Trypan blue exclusion. Cells were plated at the same initial density for each time point (see Methods). The indicated times refer to DEX treatment, so that the $24 \mathrm{~h}$ point represents 5 days' total NGF exposure with inclusion of DEX just for the last $24 \mathrm{~h}$. ANOVA across all concentrations and time points is shown at the top of each panel and the number of determinations at each time and concentration is shown in parentheses. $*$ Denotes individual values that differ from the corresponding control $(0 \mu \mathrm{M})$. NS, not significant.

TH as compared to undifferentiated cells: ca. $900 \mathrm{pmol} / \mathrm{h} / \mu \mathrm{g}$ DNA (Figure $6 \mathrm{a}$ ) or $32 \mathrm{pmol} / \mathrm{h} / \mu \mathrm{g}$ protein, as compared to 350 and 19 units, respectively. After $72 \mathrm{~h}$ exposure to DEX, $\mathrm{TH}$ was increased even further, whether evaluated per cell (Figure 6a) or per unit protein (Figure 6b). Notably, the effect on $\mathrm{TH}$ represented a $30 \%$ increase above that seen with NGF alone, a larger proportional increase than was obtained with the same DEX treatment in undifferentiated cells. In contrast, DEX treatment in mid-differentiation reduced ChAT only by about $10 \%$ (Figure $6 \mathrm{a}$ and b). For ChAT, then, the effect of introducing DEX in middifferentiation was less deleterious than when it was included from the start of differentiation.

\section{DISCUSSION}

Our results indicate that DEX directly targets neurodevelopment in stages ranging from cell replication and growth, through early differentiation, neurite formation, and phenotypic specialization, and does so at concentrations well below those required for therapeutic intervention in preterm infants. There are a number of important ramifications of this basic finding. First, glucocorticoid use in preterm labor could contribute directly to adverse neurobehavioral outcomes, over and above the confounds of preterm delivery or of secondary effects on the maternalfetal unit, maternal-neonatal interactions, or maternal or offspring neuroendocrine function. Second, the wide window of vulnerability of neurodevelopment to disruption by DEX means that adverse effects, such as those already noted for glucocorticoid administration in vivo (Bohn, 1984; Fuxe et al, 1994, 1996; Gilad et al, 1998; Gould et al, 1997; Kreider et al, 2005a, b, 2006; Maccari et al, 2003; Matthews, 2000; Matthews et al, 2002; McEwen, 1992; Meaney et al, 1996; Weinstock, 2001; Welberg and Seckl, 2001), are likely to be exerted at any stage in the period of 24-34 weeks of gestation in which these agents are recommended for use (Gilstrap et al, 1995). Third, the targeting of multiple stages of neurodevelopment means that the net outcome will differ 

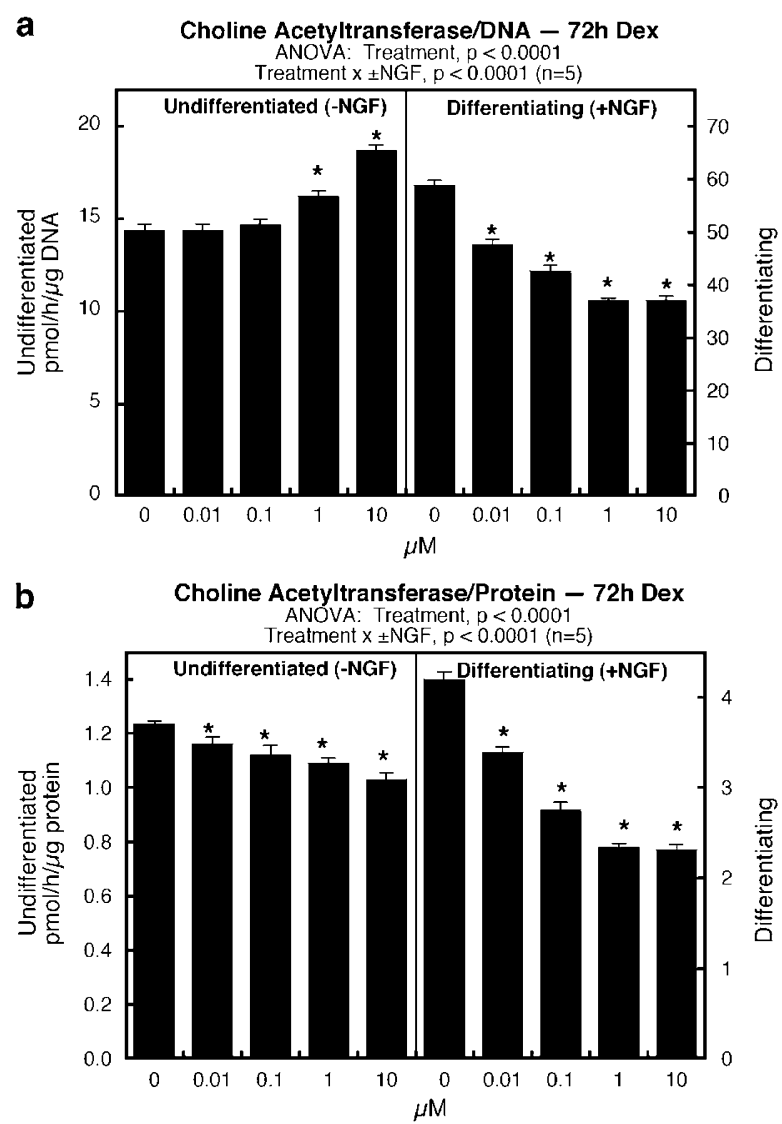

Figure 5 Concentration-response relationships for the effects of DEX on choline acetyltransferase activity: (a) activity relative to the total number of cells (activity per unit DNA) or (b) relative to total protein (activity per $\mu \mathrm{g}$ protein). Each panel shows the effects of $72 \mathrm{~h}$ of DEX treatment in undifferentiated cells (left) and in cells treated simultaneously with NGF and DEX (right). ANOVA across all concentrations and both differentiation states $( \pm N G F)$ is shown at the top of each panel and the number of determinations at each time and concentration is shown in parentheses. * Denotes individual values that differ from the corresponding control $(0 \mu \mathrm{M})$. Note the different scales for undifferentiated and differentiating cells.

according to the maturational timetable for neurogenesis and differentiation in each brain region (Bayer et al, 1993). Finally, the promotion of the catecholaminergic phenotype at the expense of the cholinergic phenotype raises the possibility that, even in an anatomically 'normal' region, there may be functional miswiring, with inappropriate innervation of target cells by presynaptic terminals manufacturing the 'wrong' neurotransmitter. Accordingly, the results with the PC12 cell model will be discussed below in light of the potential contributions of each type of effect to these outcomes.

A direct comparison of in vitro concentrations to those achieved in vivo is inevitably complicated by the inherent differences in time course of action, the superimposition of diurnal changes in the intact animal but not the culture system, and the catabolism of glucocorticoids in vivo but not in vitro. Nevertheless, in undifferentiated PC12 cells undergoing active mitosis, we obtained clear inhibition of cell replication at DEX concentrations as low as $0.01 \mu \mathrm{M}$, more than an order of magnitude below the concentrations

expected from typical therapy (Charles et al, 1993; Gilstrap et al, 1995; Osathanondh et al, 1977). The effect did not wane with prolonged exposure, in keeping with the situation in the developing fetus, where glucocorticoid receptors typically do not downregulate or desensitize, whereas they do in the adult (Ghosh et al, 2000). However, inhibition of DNA synthesis will have the greatest impact on final cell number when it occurs at high mitotic rates, when most of the cells are being acquired, whereas the same degree of inhibition will have less impact after mitosis has slowed. Again, this matches the regional specification of deficits of neural cells after DEX administration as reported for treatment in vivo (Bohn, 1984; Kreider et al, 2005a, 2006), reinforcing the likelihood that these, too, represent direct effects of DEX on the developing brain. Furthermore, DEX arrests mitotic activity at the $\mathrm{G}_{0} / \mathrm{G}_{1}$ phase (Greenberg et al, 2002), which contributes to its therapeutic effect in the immature lung, switching pneumocytes from replication to differentiation and thus promoting surfactant production (Gross, 1990). Given the same mechanism, but a lower 
concentration threshold for effects on neural cell division, this finding reinforces the idea that therapeutic use of glucocorticoids aimed at lung maturation will also target the developing brain.

We also observed cumulative deficits, as much as $50 \%$, in the DNA content. The reduction in mitotic index thus contributes to an actual decline in the number of neural cells, just as observed anatomically with the use of antenatal steroids in animals and humans (Bohn, 1984; Kreider et al, 2005a, 2006; Murphy et al, 2001). Furthermore, we did not observe any decrease in cell viability, effectively ruling out the possibility that DEX reduces cell number through cytotoxic actions. In fact, prolonged exposure to high concentrations of DEX actually improved cell viability, a factor which may be important in considering its interaction with other events relevant to preterm infants, as will be discussed later. Further evidence of the specific targeting of cell replication in undifferentiated cells was provided by the fact that DEX did not inhibit cell growth and in fact, promoted perikaryal enlargement as indicated by a rise in the protein/DNA ratio and a decline in the membrane/total protein ratio.

To a limited extent, then, the actions of DEX share some of the differentiation characteristics of NGF, namely the promotion of cell growth at the expense of mitotic activity. However, the effects on differentiating cells indicate that the similarities end there. As a primary differentiation signal, NGF promotes neurite formation and membrane complexity, evidenced by the sharp increase in membrane/total protein ratio over and above the rise in total proteins reflecting overall cell growth. In contrast, DEX administration begun at the onset of differentiation reduced the membrane/total protein ratio, implying an inhibitory effect on neuritic outgrowth. Indeed, this effect showed a different concentration-response relationship from those on perikaryal growth or cell number, reinforcing the concept that it represents a separable outcome. Our results thus are in agreement with impaired neurite formation reported earlier at much higher concentrations (Unsicker et al, 1978) and as found more recently in our studies with DEX treatment in vivo, including doses below those in therapeutic use (Kreider et al, 2005a,2006). Effects on this aspect of cell differentiation are likely to contribute to the observation that, even in brain regions that are largely finished with neurogenesis at the time of glucocorticoid therapy, DEX administration elicits reductions in volume (Murphy et al, 2001). Also, in this phase, as was true for undifferentiated cells, high DEX concentrations did not decrease cell viability and actually reduced the proportion of cells showing trypan blue staining.

With the initiation of differentiation, a number of the DEX effects showed a shift in sensitivity, magnitude, and direction of change, supporting the concept that the actions during phases in which neural cells are dividing differ substantially from those that occur during specialization. This conclusion is reinforced by our findings with the third treatment model, where DEX was introduced in middifferentiation, after the cells had already undergone 4 days' NGF pretreatment. We still observed a cumulative deficit in cell number but to a smaller extent than in undifferentiated cells; again, this reflects the fact that the compromise of cell acquisition occurs at all stages, with the greatest effect reflecting high rates of mitosis rather than a higher inherent sensitivity to DEX. However, both the inhibition of neurite outgrowth and the improvement in cell viability were less evident in differentiating cells, implying that these effects wane in mid-differentiation. Again, the results in the PC12 model recapitulate our findings for in vivo DEX treatments (Kreider et al, 2005a, 2006).

The results obtained for expression of the cholinergic $v s$ catecholaminergic phenotype provide the strongest evidence for a critical period of vulnerability centered around early as opposed to later stages of differentiation. In undifferentiated cells, DEX increases TH activity because of the presence of a glucocorticoid response element in the promoter of the TH gene (Hagerty et al, 2001). Here, we found that DEX also increased ChAT expression on the basis of activity per cell but not on the basis of activity per unit protein. Again, this is consistent with a prodifferentiation signal from DEX administration, but one where the effects on the cholinergic phenotype are smaller than the promotional effects on growth and the consequent rise in total protein per cell. In turn, this dichotomy points out the importance of considering the effects of DEX when superimposed on large changes in cell number and size that have different concentration-response relationships, factors that have not been considered heretofore (Berse and Blusztajn, 1997; Lucas and Thoenen, 1977); obviously, these are critical to determining whether there are direct effects of DEX on different neuronal phenotypes when used in a therapeutic setting, over and above those that might be secondary to neural cell acquisition or growth. These considerations become more important with the rise in activity seen as differentiating cells specialize into the two different phenotypes. As expected (Teng and Greene, 1994), NGF-induced differentiation produced a large increment in both ChAT and $\mathrm{TH}$ activities, whether assessed on a per cell basis or relative to total protein. However, whereas DEX increased TH activity, it decreased ChAT, again at concentrations orders of magnitude below those required for clinical utility. Furthermore, the effects were greater when DEX was included from the start of differentiation than when cells were allowed to reach mid-differentiation before the beginning of DEX treatment. Accordingly, it is highly likely that DEX acts at the point at which cells first determine their phenotypic fate, to a much greater extent than it does once that decision has been made. For the cholinergic phenotype, the effect in differentiating cells is thus completely opposite to that in undifferentiated cells, where ChAT per cell was actually increased by DEX; the critical period thus involves a transition from promotional effects to inhibitory effects that then wane as differentiation proceeds. Furthermore, the fact that suppression of the cholinergic phenotype is achieved with promotion of the catecholaminergic phenotype raises the possibility of developing neurons making the 'wrong' phenotypic decision, thus producing a mismatch between the neurotransmitter contained within a presynaptic terminal and the receptor population at the postsynaptic site. Our results thus match closely the suppression of the enzymes responsible for acetylcholine biosynthesis and promotion of those responsible for catecholamine biosynthesis, and for the enhanced expression of adrenergic receptors noted previously for glucocorticoid effects on developing neurons 
in vivo and in vitro (Berse and Blusztajn, 1997; Black, 1978; $\mathrm{Hu}$ et al, 1996; Kreider et al, 2005a, 2006). Again, these are likely to contribute to the long-term alterations in cholinergic synaptic proteins, synaptic activity and related behaviors seen in animal models of perinatal DEX administration (Kreider et al, 2005a, b, 2006) and cognitive dysfunction in humans (Yeh et al, 2004).

Finally, DEX evoked a significant improvement in cell viability in undifferentiated cells or at early stages of differentiation, although we evaluated only the highest DEX concentration in the present study. In contrast, NGF by itself reduced viability, a finding in keeping with the rise in oxidative stress that attends early stages of differentiation (Katoh et al, 1997; Qiao et al, 2005). One possibility, then, is that DEX reduces oxidative stress in differentiating neural cells, an effect that could contribute to apparent protective actions of this treatment toward hypoxic-ischemic brain damage (Barks et al, 1991). On the other hand, a moderate degree of oxidative stress actually provides one of the normal ontogenetic signals that initiates differentiation and is also required to prevent apoptotic cell death (Ikeda et al, 2002; Katoh et al, 1997; McCollum et al, 2004). The key factor may then be both the dose and timing of DEX administration. In fact, depending on the dose, treatment period, and brain region, DEX administration can also worsen hypoxia-induced damage (Carlos et al, 1991). Here, the improvement in cell viability was noted at a concentration well above those at which DEX interfered with neurogenesis and differentiation, suggesting that the protective effect may require doses far in excess of those that are themselves damaging to brain development. Clearly, future studies will need to address the dichotomies in vulnerable periods and dose-effect relationships for these competing outcomes.

There is increasing evidence that the benefits of glucocorticoid therapy of preterm infants comes at significant risk to future health (Blackmon et al, 2002; Coe and Lubach, 2005; Newnham, 2001; Raff, 2004; Seckl, 2004). Our results reinforce the fact that brain development is among the processes most vulnerable to glucocorticoids, with disruption of cell acquisition and differentiation achieved at concentrations well below those required for therapeutic interventions. The demonstration of these actions in neural cell cultures, reproducing all the essential findings from glucocorticoid treatment in vivo (Bohn, 1984; Fuxe et al, 1994, 1996; Gilad et al, 1998; Gould et al, 1997; Kreider et al, 2005a, b, 2006; Maccari et al, 2003; Matthews, 2000; Matthews et al, 2002; McEwen, 1992; Meaney et al, 1996; Weinstock, 2001; Welberg and Seckl, 2001), indicates that disrupted neurodevelopment is a direct glucocorticoid effect, not secondary to growth impairment, neuroendocrine disruption or other confounding actions in the fetus, neonate or mother. The successful prevention of respiratory distress in tens of thousands of preterm infants annually in the USA needs to be balanced against the adverse effects on brain development in the hundreds of thousands of individuals that receive the treatment.

\section{ACKNOWLEDGEMENTS}

This work was supported by NIH Grants ES10356 and ES07031.

\section{REFERENCES}

Barks JDE, Post M, Tuor UI (1991). Dexamethasone prevents hypoxic-ischemic brain damage in the neonatal rat. Pediatr Res 29: $558-563$.

Bayer SA, Altman J, Russo RJ, Zhang X (1993). Timetables of neurogenesis in the human brain based on experimentally determined patterns in the rat. Neurotoxicology 14: 83-144.

Bell JM, Whitmore WL, Slotkin TA (1986). Effects of $\alpha$ difluoromethylornithine, a specific irreversible inhibitor of ornithine decarboxylase, on nucleic acids and proteins in developing rat brain: critical perinatal periods for regional selectivity. Neuroscience 17: 399-407.

Berse B, Blusztajn JK (1997). Modulation of cholinergic locus expression by glucocorticoids and retinoic acid is cell-type specific. FEBS Lett 410: 175-179.

Black IB (1978). Regulation of autonomic development. Ann Rev Neurosci 1: 183-214.

Blackmon LR, Bell EF, Engle WA, Kanto WP, Martin GI, Miller CA et al (2002). Postnatal corticosteroids to treat or prevent chronic lung disease in preterm infants. Pediatrics 109: 330-338.

Bohn MC (1984). Glucocorticoid induced teratologies of the nervous system. In: Yanai J (ed). Neurobehavioral Teratology. Elsevier: Amsterdam. pp 365-387.

Bowman RE, MacLusky NJ, Sarmiento Y, Frankfurt M, Gordon M, Luine VN (2004). Sexually dimorphic effects of prenatal stress on cognition, hormonal responses, and central neurotransmitters. Endocrinology 145: 3778-3787.

Carlos RQ, Seidler FJ, Slotkin TA (1991). Fetal dexamethasone exposure sensitizes neonatal rat brain to hypoxia: effects on protein and DNA synthesis. Dev Brain Res 64: 161-166.

Charles B, Schild P, Steer P, Cartwright D, Donovan T (1993). Pharmacokinetics of dexamethasone following single-dose intravenous administration to extremely low birth weight infants. Dev Pharmacol Ther 20: 205-210.

Coe CL, Lubach GR (2005). Developmental consequences of antenatal dexamethasone treatment in nonhuman primates. Neurosci Biobehav Rev 29: 227-235.

Dean F, Yu C, Lingas RI, Matthews SG (2001). Prenatal glucocorticoid modifies hypothalamo-pituitary-adrenal regulation in prepubertal guinea pigs. Neuroendocrinology 73: 194-202.

Doyle LW, Ford GW, Davis NM, Callanan C (2000). Antenatal corticosteroid therapy and blood pressure at 14 years of age in preterm children. Clin Sci 98: 137-142.

Ebert SN, Lindley SE, Bengoechea TG, Bain D, Wong DL (1997). Adrenergic differentiation potential in PC12 cells: influence of sodium butyrate and dexamethasone. Mol Brain Res 47: 24-30.

Felszeghy K, Bagdy G, Nyakas C (2000). Blunted pituitaryadrenocortical stress response in adult rats following neonatal dexamethasone treatment. J Neuroendocrinol 12: 1014-1021.

Fujita K, Lazarovici P, Guroff G (1989). Regulation of the differentiation of PC12 pheochromocytoma cells. Environ Health Perspect 80: 127-142.

Fuxe K, Cintra A, Chadi G, Gustafsson JÅ, Agnati LF (1994). Central glucocorticoid receptors and neuronal plasticity. Methods Neurosci 22: 372-382.

Fuxe K, Diaz R, Cintra A, Bhatnagar M, Tinner B, Gustafsson JA et al (1996). On the role of glucocorticoid receptors in brain plasticity. Cell Mol Neurobiol 16: 239-258.

Ghosh B, Wood CR, Held GA, Abbott BD, Lau C (2000). Glucocorticoid receptor regulation in the rat embryo: a potential site for developmental toxicity? Toxicol Appl Pharmacol 164: 221-229.

Gilad GM, Gilad VH, Eliyayev Y, Rabey JM (1998). Developmental regulation of the brain polyamine-stress-response. Int $J$ Dev Neurosci 16: 271-278. 
Gilstrap LC, Christensen R, Clewell WH, D'Alton ME, Davidson EC, Escobedo MB et al (1995). Effect of corticosteroids for fetal maturation on perinatal outcomes. J Am Med Assoc 273: 413-418.

Gould E, Tanapat P, McEwen BS (1997). Activation of the type 2 adrenal steroid receptor can rescue granule cells from death during development. Dev Brain Res 101: 265-268.

Greenberg AK, Hu J, Basu S, Hay J, Reibman J, Yie TA et al (2002). Glucocorticoids inhibit lung cancer cell growth through both the extracellular signal-related kinase pathway and cell cycle regulators. Am J Respir Cell Mol Biol 27: 320-328.

Gross I (1990). Regulation of fetal lung maturation. Am J Physiol 259: L337-L344.

Hagerty T, Fernandez E, Lynch K, Wang SS, Morgan WW, Strong R (2001). Interaction of a glucocorticoid-responsive element with regulatory sequences in the promoter region of the mouse tyrosine hydroxylase gene. J Neurochem 78: 1379-1388.

Hu ZT, Yuri K, Ichikawa T, Kawata M (1996). Exposure of postnatal rats to glucocorticoids suppresses the development of choline acetyltransferase-immunoreactive neurons: role of adrenal steroids in the development of forebrain cholinergic neurons. J Chem Neuroanat 10: 1-10.

Ikeda T, Mishima K, Yoshikawa T, Iwasaki K, Fujiwara M, Xia YX et al (2002). Dexamethasone prevents long-lasting learning impairment following neonatal hypoxic-ischemic brain insult in rats. Behav Brain Res 136: 161-170.

Katoh S, Mitsui Y, Kitani K, Suzuki T (1997). Hyperoxia induces the differentiated neuronal phenotype of PC12 cells by producing reactive oxygen species. Biochem Biophys Res Commun 241: 347-351.

Kreider ML, Aldridge JE, Cousins MM, Oliver CA, Seidler FJ, Slotkin TA (2005a). Disruption of rat forebrain development by glucocorticoids: critical perinatal periods for effects on neural cell acquisition and on cell signaling cascades mediating noradrenergic and cholinergic neurotransmitter/neurotrophic responses. Neuropsychopharmacology 30: 1841-1855.

Kreider ML, Levin ED, Seidler FJ, Slotkin TA (2005b). Gestational dexamethasone treatment elicits sex-dependent alterations in locomotor activity, reward-based memory and hippocampal cholinergic function in adolescent and adult rats. Neuropsychopharmacology 30: 1617-1623.

Kreider ML, Tate CA, Cousins MM, Oliver CA, Seidler FJ, Slotkin TA (2006). Lasting effects of developmental dexamethasone treatment on neural cell number and size, synaptic activity and cell signaling: critical periods of vulnerability, dose-effect relationships, regional targets and sex selectivity. Neuropsychopharmacology 31: 12-35.

Lau C, Seidler FJ, Cameron AM, Navarro HA, Bell JM, Bartolome J et al (1988). Nutritional influences on adrenal chromaffin cell development: comparison with central neurons. Pediatr Res 24: 583-587.

Lucas CA, Thoenen H (1977). Selective induction by glucocorticoids of tyrosine hydroxylase in organ cultures of rat pheochromocytoma. Neuroscience 2: 1095-1101.

Maccari S, Darnaudery M, Morley-Fletcher S, Zuena AR, Cinque C, Van Reeth O (2003). Prenatal stress and long-term consequences: implications of glucocorticoid hormones. Neurosci Biobehav Rev 27: 119-127.

Matthews SG (2000). Antenatal glucocorticoids and programming of the developing CNS. Pediatr Res 47: 291-300.

Matthews SG, Owen D, Banjanin S, Andrews MH (2002). Glucocorticoids, hypothalamo-pituitary-adrenal (HPA) development, and life after birth. Endocr Res 28: 709-718.

McCollum AT, Jafarifar F, Chan R, Guttmann RP (2004). Oxidative stress inhibits ionomycin-mediated cell death in cortical neurons. J Neurosci Res 76: 104-109.

McEwen BS (1992). Steroid hormones: effect on brain development and function. Hormone Res 37: 1-10.
Meaney MJ, Diorio J, Francis D, Widdowson J, LaPlante P, Caldji C et al (1996). Early environmental regulation of forebrain glucocorticoid receptor gene expression: implications for adrenocortical responses to stress. Dev Neurosci 18: $49-72$.

Muneoka K, Mikuni M, Ogawa T, Kitera K, Kamei K, Takigawa M et al (1997). Prenatal dexamethasone exposure alters brain monoamine metabolism and adrenocortical response in rat offspring. Am J Physiol 42: R1669-R1675.

Murphy BP, Inder TE, Huppi PS, Warfield S, Zientara GP, Kikinis $\mathrm{R}$ et al (2001). Impaired cerebral cortical gray matter growth after treatment with dexamethasone for neonatal chronic lung disease. Pediatrics 107: 217-221.

Newnham JP (2001). Is prenatal glucocorticoid administration another origin of adult disease? Clin Exp Pharmacol Physiol 28: 957-961.

Osathanondh R, Tulchinsky D, Kamali H, Fencl M, Taeusch HW (1977). Dexamethasone levels in treated pregnant women and newborn infants. J Pediatrics 90: 617-620.

Qiao D, Seidler FJ, Slotkin TA (2005). Oxidative mechanisms contributing to the developmental neurotoxicity of nicotine and chlorpyrifos. Toxicol Appl Pharmacol 206: 17-26.

Raff H (2004). Neonatal dexamethasone therapy: short- and longterm consequences. Trends Endocrinol Metab 15: 351-352.

Reznikov AG, Nosenko ND, Tarasenko LV (2004). Early postnatal effects of prenatal exposure to glucocorticoids on testosterone metabolism and biogenic monoamines in discrete neuroendocrine regions of the rat brain. Comp Biochem Physiol C 138: $169-175$.

Schubert D, LaCorbiere M, Klier FG, Steinbach JH (1980). The modulation of neurotransmitter synthesis by steroid hormones and insulin. Brain Res 190: 67-79.

Seckl JR (2001). Glucocorticoid programming of the fetus: adult phenotypes and molecular mechanisms. Mol Cell Endocrinol 185: $61-71$.

Seckl JR (2004). Prenatal glucocorticoids and long-term programming. Eur J Endocrinol 151: U49-U62.

Slotkin TA, Lappi SE, Tayyeb MI, Seidler FJ (1991). Dosedependent glucocorticoid effects on noradrenergic synaptogenesis in rat brain: ontogeny of $\left[{ }^{3} \mathrm{H}\right]$ desmethylimipramine binding sites after fetal exposure to dexamethasone. Res Comm Chem Pathol Pharmacol 73: 3-19.

Slotkin TA, Persons D, Slepetis RJ, Taylor D, Bartolome J (1984). Control of nucleic acid and protein synthesis in developing brain, kidney, and heart of the neonatal rat: effects of $\alpha$ difluoromethylornithine, a specific, irreversible inhibitor of ornithine decarboxylase. Teratology 30: 211-224.

Song X, Violin JD, Seidler FJ, Slotkin TA (1998). Modeling the developmental neurotoxicity of chlorpyrifos in vitro: macromolecule synthesis in PC12 cells. Toxicol Appl Pharmacol 151: 182-191.

Teng KK, Greene LA (1994). Cultured PC12 cells: a model for neuronal function and differentiation. In: Celis JE (ed). Cell Biology: A Laboratory Handbook. Academic Press: San Diego. pp 218-224.

Thai L, Galluzzo JM, McCook EC, Seidler FJ, Slotkin TA (1996). Atypical regulation of hepatic adenylyl cyclase and adrenergic receptors during a critical developmental period: agonists evoke supersensitivity accompanied by failure of receptor downregulation. Pediatr Res 39: 697-707.

Trauth JA, Seidler FJ, Slotkin TA (2000). An animal model of adolescent nicotine exposure: effects on gene expression and macromolecular constituents in rat brain regions. Brain Res 867: 29-39.

Unsicker K, Krisch B, Otten U, Thoenen H (1978). Nerve growth factor-induced fiber outgrowth from isolated rat adrenal chromaffin cells: impairment by glucocorticoids. Proc Natl Acad Sci 75: 3498-3502. 
Weinstock M (2001). Alterations induced by gestational stress in brain morphology and behaviour of the offspring. Prog Neurobiol 65: 427-451.

Welberg LAM, Seckl JR (2001). Prenatal stress, glucocorticoids and the programming of the brain. J Neuroendocrinol 13: 113-128.

Winick M, Noble A (1965). Quantitative changes in DNA, RNA and protein during prenatal and postnatal growth in the rat. Dev Biol 12: $451-466$

Yeh TF, Lin YJ, Lin HC, Huang CC, Hsieh WS, Lin $\mathrm{CH}$ et al (2004). Outcomes at school age after postnatal dexamethasone therapy for lung disease of prematurity. $N$ Engl J Med 350: 1304-1313.

Zahalka EA, Seidler FJ, Slotkin TA (1993). Dexamethasone treatment in utero enhances neonatal cholinergic nerve terminal development in rat brain. Res Comm Chem Pathol Pharmacol 81: 191-198. 